\title{
Significance of Market Segmentation to Strategic Marketing in Nigeria and its Impact on Global Education, Research and Technology for Sustainable Development
}

\author{
(A Case Study of Kaduna Flour Mill)
}

\author{
Article by Alhaji Umar Lawal Aliyu \\ PhD in Management, Texila American University, Guyana \\ E-mail: aliyufad@gmail.com
}

\begin{abstract}
The growth, profit and survival of any firm irrespective of its policies relies positively on how well the consumers wants and needs are satisfied by the firm's products or services and this can inversely be improved by global education, research and technology for sustainable development. It is through marketing that a firm can identify and offer products that will satisfy the wants and needs of customers or consumers and also cause sustainable growth and development.

By tailoring marketing programs to individual marketing segments, management can do a better marketing job and make more efficient use of marketing resources. This study then seeks to look at the application of market segmentation and its significance to strategic marketing in Nigeria and how it can improve global education, research and technology for sustainable development by using a case study of Kaduna Flour Mill. Detailed and current background information about Kaduna Flour Mill and their products was obtained while personal interviews were conducted at different locations in the metropolis to ascertain the extent to which the company applies market segmentation in marketing their numerous products. However, the findings of this research study are analyzed and discussed in chapter four while conclusion and recommendation were drawn and made in chapter five.

The micro environment includes, naturally, actors like customers, suppliers and intermediaries, competitors, as well as investors and financial institutions, and in addition also the media, communities, the government, different interest groups and the public. Customers, regardless whether they are individual consumers, other businesses, retailers or public service providers, can probably be regarded as the most important factor when considering the strategic approach to sustainable development.
\end{abstract}

\section{Introduction}

In both advanced are less developed countries, economic management is a traditional demand of Government irrespective of economic and political philosophy. One of the major pre-occupations of every private and public enterprise is the maintenance and sustainable growth and development.

To survive growth, flourish business and sustainable development it is inevitable that you must device market segmentation for dealing with environmental forces such as change in population, education, research, income level, taste, sophistication and technology, competition etc. Market segmentation is a customer orientation tools or philosophy that identifies the customer needs within a sub-market (segment) and satisfies the customer needs within a sub-market (segment) and satisfies them in an efficient and profitable manner.

\section{Background of the study}

All organizations whether public or private, manufacturing or service, large or small have a need for marketing. As a means for serving the needs of their customers marketing forms the cornerstone discipline of most successful Companies and Governments not only in developed countries but also in developing countries.

The very fact that buyers differ in their taste and preferences or scattered worldwide makes market segmentation almost inevitable that must be employed. As rightly observed by an advertisement agency, there will be no market for products that people like little but only for product that people like a lot. Furthermore, most of this kind of people will be unevenly spread in various locations and this causes the need for market segmentation. 
This citation above clearly indicates the needs to identify the various needs and differences of the customers classify them into groups and then tailor the product to each group. This is what market segmentation does.

Market segmentation also is conformity with the philosophy of market concept which is employed by most firms today as their guiding philosophy. Marketing concept is philosophy which hold that goal consist of the desired needs and wants more effectively and efficiently than the competitors (Philip. K 1980).

The heterogeneity of the market place make it infeasible to implement the marketing concept using a single market tools aimed at all buyers instead, market segmentation occurs. You have to aim at somebody not just everybody to make profit.

By definition, claimed by Belz (2005), sustainable products make a contribution to the solution of socio-ecological problems and have some kind of a competitive advantage over other products with respect to the socio-ecological dimension.

\section{Objective of the study}

This study is aimed at achieving the following:

- To determine the extent to which application of market segmentation as a tool by organizational assist them in achieving their objectives.

- To analyze market segmentation and identify it as a tool for organizational growth and survival in Nigeria.

- To identify various basis for market segmentation applied by organizations in Nigeria.

- To bring into focus the various factors influencing the effective application of market segmentation as a tool by organization in Nigeria.

- To make recommendation for improvement.

\section{Research hypothesis}

That Kaduna Flour Mill uses market segmentation as form of strategy for marketing to achieve sustainable growth.

That market segmentation as form of strategic marketing has significantly assisted Companies in achieving their marketing objectives.

A way to discover the new segment is to investigate the hierarchy of attribute that consumer look at and their way to choosing a brand. Focusing on a segment of the market brings about more profitability and satisfaction.

\section{Scope and limitation of the study}

The study is on Kaduna Flour Mill. The research on market segmentation significance to strategic marketing in Nigeria and its impact on global education, research and technology for sustainable development is such a wide topic that an extensive treatment of it is not possible because of the limited amount of time at the researcher's disposal so the research focuses its attention on the Kaduna Flour Mill. The research work will also put emphasis only on the marketing aspect.

Keywords: Employer, employee, organization, motivation, management, satisfaction, performance and goals, market, product, strategy, determination, goals, objective, and enterprise.

\section{Literature review}

This chapter reviews literature related to the crucial aspects that is needed to be acquainted with and as well as the contemporary issues that are specifically related directly or indirectly to the research topic market segmentation as a tool for growth and survival. This chapter contains the following headings under which the literature is viewed the concept of market segmentation, steps in market segmentation, bases for segmenting consumer market, bases for segmenting industrial market, alternative segmentation strategies, analytical technique used to segment a market, market segmentation and product positioning the merit of market segmentation and the merits and demerit of market segmentation.

Market segmentation in simple words may be defined as a process of splitting or dividing potential customers into certain groups or segments sharing similar levels of needs. The definition explains that 
the process is simply a division of markets into target groups. It is creating sub-sets of a market based on similar characteristics of consumers with similar demands and providing them with a product to satisfy their need in a much better way than it could have been otherwise.

Do we need to segment the Market? Marketing may be based on broad markets or small subsegments. Mass marketing is the process or strategy to use the same marketing channels for all consumers without identifying the needs of a specific group of people. Mass marketing strategy employs mass promotion, mass production and mass distribution in the same way for mass consumers. In the past, companies have used mass marketing to achieve the economies of scale. However, times have changed, and it is almost impossible to create products to appeal to the entire market. Pursuing this strategy, several companies have lost their market leadership or a considerable chunk of their market share. An example would be Ford Motors when they offered T Model to all buyers "in any color as long as it is black." This is why there is a need of market strategy based on specific groups of customers as buyers' needs are different; they cannot be satisfied the same way. The division of markets into various sub groups on the basis of several variables will more closely match particular needs of a particular group of consumers.

\section{The concept of market segmentation}

Market is a place where people meet to buy and sell goods and services. Market segmentation is the process of dividing the total heterogeneous market for a product into sub market or segmentation each of which tends to be homogenous.

Station (1981) however maintains that market segmentation is a customer oriented philosophy. It can be achieved by identifying customer needs and wants within sub market segmentation and satisfying those needs.

Kotler P. (1985) defined market segmentation as a process of dividing a market to distinct group of buyer who might require separate products or market mix. Company identifies different ways of segmenting a market and develops profits of the suit market segmentation.

According to Bush and Houston (1985) market segmentation is the process by which an organization attempts to match a tool marketing program to the unique manner in which one or more customer groups behave in the market place. The definition recognized segmentation as a process involving a sequence of steps; identifying the segments, analyzing the nature of each segment to determine its uniqueness, translating these differences into appropriate marketing strategy and select target markets.

According to Boone .L and Kurtz .D (1971), they viewed market segmentation as a process that involves companies producing numerous separate products and designing different mixes to satisfy smaller homogenous of the total market. The logic behind market segmentation is that organization only survives because they have customers and these customers are people. Every given society / Environment market is made up of a numerous people with different cultural backgrounds, different religious beliefs, variation in purchasing power and several other differences. On the whole despite the varying approaches of the differences writers, they suggest the same thing. That is you have to have somebody and not just everybody to make a profit.

\section{Bases for segmentation}

There is no particular right way of segmenting a market in other words. This means a market can be segmented in a number of ways by using many variables. According to W. Stanton, buyer behaviors are rarely related to only one type of segmentation but factors can be so closely related. One of the very important ways of segmenting the entire Nigerian market is to divide it into ultimate and industrial users.

The distinct on between consumer and industrial market is very important from a marketing point of view because the two markets buy differently. It is well known that the composition of a sellers marketing program i.e. the brand of the elements of the marketing mix depend upon whether it is directed toward the consumer market s or industrial market.

According to W. Station the ultimate consumers buy and use product and services for personal and household use. They are satisfying strictly non-business wants and they constituted what is called the consumer market (Stanton W J Fundamental of marketing 6th Edition P. 79) 1981. Stanton further states that industrial users are business, industrial or institutional organization that buy product or 
services to use in Mr own business or make other product.

\section{Condition for effective segmentation}

Clearly, there are many ways to segment a market. Not all segmentations however are effective. Kotler P (1985) identified that for market segmentation to be useful, the segment must exhibit the following characteristics.

I. Measurability: There must be a shared characteristic that can be used to include and exclude consumers from the group. According to Paul S. B and Michael J .H (1985) it can be identified as a segment, a buying unit whether on individual consumer, household or organization must be measurable on the chosen variable. It must be clearly identifiable in terms of the segment of the market to which it belongs.

II. Substantiality: Paul S .B and Michael J H (185) the segmentation process which yield at least one segment that is sufficiently large in profit potential to make it worthwhile as a target market. A segment may meet all the above criteria but be too small to be a profitable target market.

III. Stability: the sequence of step in the segmentation process usually encompasses insider able range or time.

In particular, there will be a gap between when segment information is collected and analyzed and when a marketing strategy based on his information is implemented and performance objective can be realized. It is necessary then for a market segment to the highly stable with respect to the appropriate market strategy. The segment much remains much the same from when information is analyzed to when the appropriate strategy for it is implemented. If the market is unstable, the marketing strategy directed at it becomes inappropriate and the benefits of segmentation may be less than otherwise.

Morrison (1989) suggests that three other requirements should be further evaluated and these are:

(i). Defensible (the marketing firm must ensure that each group requires individual attention).

(ii). Durable (some market segments are short time)

(iii). Competitive (relative to market segmentation).

\section{Merit of market segmentation}

According to Philip Kotler .P (1991), both the marketing firms and its customer derive benefits from market segmentation and the benefit are:

(i). Effective segmentation should result in improved allocation of market resources which will have an adverse good effect on the growth and development of a country as a whole.

(ii). Segmentation enables the producers to design product and market appeals to satisfy the needs of the groups

(iii). Effective segmentation allows for greater consumer satisfaction and this can cause sustainable growth

(iv). Effective segmentation result in greater sale volume and profitability which can cause rise in GDP which will in turn result to sustainable growth.

(v). Segmentation makes for better competitive position for existing brand in the market place.

(vi). It is easier to understand the exact needs of the customer and target the marketing strategy at a particular group. It is much easier and more successful to create and promote specific and customized products and services which will in turn lead to company and economic growth.

(vii). Mass marketing is a strategy of the past. Target marketing and positioning creates new potential customers and new ideas for new products and services. Companies can create better products and hence maximize their potential profit.

(viii). Specific groups require specific products. Thus segmenting the markets creates further opportunities for business and economic growth and development.

(ix). It is a great way to retain customers. Firms can establish a life-long relationship with their consumers via formulating an effective market segmenting strategy with can also lead to long lasting sustainable growth and development.

(x). the company's resources are utilized for producing the right product for the right customer.

(xi). Segmenting business and consumer markets is important to maintain existing market share and expand it. A successful company needs to gain competitive advantage by looking closely at the 
specific needs of customers and devising strategies to provide maximum benefit, value and sustainable growth and development.

\section{Methodology}

The third chapter is an analysis of the research methodology used in the process of carrying out this research work.

The methodology includes; research design, population of the study, sample size and technique, method of data collection and method of data analysis.

\section{Research design}

A survey research design was used for this study. This is because survey method is concerned with ascertaining the conditions which prevail in a group of classes chosen for study. It is based essentially on a method of quantitative description of the general characteristics of the group being studied.

\section{Population of the study}

For the purpose of this research, a sample of the entire population will be studied in place of the entire population. The population of the study is the combination of consumers of Kaduna Flour Mill that were sampled from Kaduna State.

\section{Method of data collection}

Personal interview was used as a method of collecting data. This is the most feasible in this kind of research where a lot of people including not educated people were contacted.

\section{Method of data analysis}

The analysis and tabulation were done using the simple percentage technique as the methods are useful mainly for the purpose of aiding comparisons.

\section{Data analysis}

This chapter presents and analysis the data obtained and the hypothesis developed in chapter one. The guided interview questions were directed to some top executives of the company while the questionnaires were directed toward some consumers.

A management response showing the different product they produced that makes them heterogeneous

According to the management of Kaduna Flour Mill they produce number of products to satisfy the growing need of the population. The different products they produce are:

(i). Semovita

(ii). Spaghetti and

(iii). Flour

\section{How they segment their market}

\section{Segments personal product}

\begin{tabular}{|l|l|l|l|}
\hline Semovita & Big size & Medium size & Small size \\
\hline Spagetti & Normal size & Slim size & Nil \\
\hline Flour & Big size & Nil & Small size \\
\hline Rice & Big size & Medium size & Small size \\
\hline
\end{tabular}

The management divided this heterogeneous market into homogenous based on the product.

\section{Testing hypothesis}

The study set out the following hypothesis:

Hi. That Kaduna Flour Mills company uses market segmentation as a form of marketing strategy.

The hypothesis is drawn up because of the significance of market segmentation to be observed in Kaduna flour mill, we must first certify that the companies use segmentation as a market strategy.

The type of strategy used in segmenting a market identify opportunity for defining the customer 
which lead to increase in sales as an objective of the firm.

Diagram in 4.2 above shows the type of strategy used by Northern Nigerian flour mill which leads to the increase in sales and how they reach the consumer through different segment which has also help the company in identifying an opportunity for more segment in order to satisfy the consumers. Which will in turn lead to increase in sale for the company which therefore makes the hypothesis is valid.

From the above table we see that market segmentation as form of strategic marketing which has significantly assisted the companies in achieving its marketing goals.

\section{Summary findings}

The following are the findings of the study

(i). Kaduna Flour Mill uses market segmentation strategy as a form of strategy for marketing.

(ii). Market segmentation as a tool for growth and survival has assist the company in achieving its marketing goals and objectives

(iii). Market segmentation if properly formulated and implemented to enhance the market share of the manufacturing company.

(iv). Market segmentation is simple, as it may seem theoretically is a lot more demanding in practices.

(v). Market segmentation as a tool for growth and development can improve global education, research and technology for sustainable development.

(vi). The growth, profit and survival of any firm irrespective of its policies relies on positively on how well the consumers wants and needs are satisfied by the firm's products or services and this can inversely improve global education, research and technology for sustainable development.

(vii). Finally, It is through marketing that a firm can identify and offer products that will satisfy the wants and needs of customers or consumers and also cause sustainable growth and development.

(viii). Customers, regardless whether they are individual consumers, other businesses, retailers or public service providers, can probably be regarded as the most important factor when considering the strategic approach to sustainable development.

\section{Summary}

In the first chapter, the study introduced the topic of the research, explained why the study is conducted and the objectives of the study. The research hypothesis, significance and the limitations of the study were also identified.

Furthermore requirements and importance of market segmentation are equally mentioned.

The third chapter presented the population of the study, method of data collection, sampling size and sampling technique and so also the draft research instrument was presented.

The forth chapter analyzed and interprets the collected data. Here the various responses obtained from the interviews and personal observations are analyzed and interpreted accordingly and in conclusion the hypotheses are tested.

Sequel to this is the last chapter which presents the summary, conclusion and recommendations.

\section{Conclusion}

"If you are not talking about segmentation, you are not talking about marketing" as stated by Theodore 2005. This is a justified conclusion from the result analyzed and discussed in this study.

The importance and significance of market segmentation as form of strategic marketing as displayed by the result is quite overwhelming and can have a positive impact on global education, research and technology for sustainable development.

It is also pertinent to note that despite the importance of marketing segmentation, proper analysis should be carried out therefore embarking on the process. Important question like "How much does the marketing segmentation cost? How many segments should a company have? All these questions should be asked and proper answers should be provided.

Unfortunately, though in practices, there is no definite answer. Experience, institution, statistical results and common sense all must be applied to decide the most suitable answers.

Finally, it will be good to understand that Customers, regardless whether they are individual consumers, other businesses, retailers or public service providers, can probably be regarded as the most 
important factor when considering the strategic approach to sustainable development in improving global education, research, technology for sustainable development and in fact all aspects of life.

\section{Recommendation}

(i). when distinct brand of product are produced, effort must be made to position the brands well and also make sure the brand reaches the targeted customers. The contrary is quite evident in the new small size bag of flour. It is intended to be a very low priced and high quality product but somehow, the product is yet to be well known to buyers some buyers even regard it to be for the high income earners. More publicity and positioning is needed here to correct such type of wrong psychology disposition of buyers.

(ii). some brand of product properly segmented are quite scarce or even loss in the market. This situation should be avoided as it rendered the market segmentation incomplete and consequently less effective.

(iii). the Semovita bags segmented on the basis of level of income has been a success. The researcher recommends that a deeper research should be carried out on the size of the product and geographical factors should be considered as criteria for segmenting the product

(iv). finally, the researcher suggest that the production should be segmented to include smaller sachet for students that cannot afford the smaller bags as this will further increase the market shares of the manufacturing company.

\section{References}

[1]. A History of Nigeria Book by Toyin Falola 1989.

[2]. Adeleye, A.S (1995): Marketing Principles and Practices 1st Edition.

[3]. Barkern, M J (1983\}: Marketing Theory and Practices, 2nd Edition, Macmillan, London.

[4]. Busch S.P \& Houston JM (1995): Marketing strategy foundation 1st Edition. Homewood, Illinois, USA.

[5]. Buskirk, H.R (2000): Principles of Marketing 4th Edition Ddryden Press U.S.A.by Murrell G. Shields.

[6]. Capital Ideas: The improbable - Peter Benstein.

[7]. Carpenter M A \& Sanders W G 2009.

[8]. Comprehensive Economics for Senior Secondary School - Johnson U. Anyaele.

[9]. Crowe and Avison (1982 AND Walter I. Kennevan 2001.

[10]. Data response on economics - O. Sanni.

[11]. E-Business and Erp: Rapid Implementation and Project Planning (Hardcover).

[12]. Essential Economics for Senior Secondary Schools - C. E. Andy.

[13]. Everitt, B.S., Landau, S. and Leese, M. (2001), Cluster Analysis, Fourth edition, Arnold.

[14]. Fundamental Principles of Economics for the Certificate year - R.A.I. Anyanwuocha.

[15]. Fundamentals of Economics - R.A.I. Anyanwuocha.

[16]. Good to great by James c collins 2001.

[17]. Harry kraemer on leadership.

[18]. Hughes J.R.T. (1972) - Industrialization, Economic Aspects.

[19]. International Exoberance - Robert J Shiller 2000.

[20]. Investments: An Introduction Prof. Dr AP Faure.

[21]. J.O. Onah (2000): Marketing in Nigeria, Experience in a developing Economy, 1st Edition, Pitmaft Press.

[22]. Jun Xu, Mohammed Quaddus. (2010) Managing Information Systems: Ten Essential Topics,(1st Edition)

[23]. Kotler. P (2000): Marketing Management: Analysis, Planning Implementation and Control 69th Edition prentice Hall; Inc. Kotler. P (1980): Principles of Marketing 4th Edition, Pp. 16 (1980) Englewood, prentice Hail $\mathrm{N} \mathrm{J}$.

[24]. Lean Performance ERP Project Management: Implementing the Virtual Lean Enterprise (Hardcover) by Brian J. Carroll.

[25]. Lucas, 1978 AND Murdick and Ross, 1975 AND Davis and Olson (1984).

[26]. Managerial and Cost Accounting Christopher J. Skousen, Larry M. Walther.

[27]. MC Carthy EJ. \& Oferreaykty N.D. JR (1985): Basic Marketing, 8th Edition 1974 Homewood. Iriwin.

[28]. New Approach Economics - K. U. Niadi\& A. B. Falodun.

[29]. Nwokeye N.G. Modern Marketing in Nigeria (1990) Macmillan Publishers, London.

[30]. Perspectives on Nigeria's Economic Development Book by Pascal G. Dozie December 1999. 
DOI: $10.21522 /$ TIJMG.2015.03.02.Art003

ISSN: $2520-310 \mathrm{X}$

[31]. Philip K. (1999) - Marketing Management Millennium edition, Practice Hall International.

[32]. Porter, Michael E. 2001. Clusters of Innovation: Regional Foundations of U.S. Competitiveness Washington, D.C.: Council on Competitiveness.

[33]. Portfolio Theory \& Financial Analyses Robert Alan Hill.

[34]. Production Planning and Control with SAP ERP (Hardcover) by Jawad Akhtar.

[35]. Project management body of knowledge 2013.

[36]. Reminiscence on Stock operator - Edwin Lefvri 1923.

[37]. Securities and Exchange Commission (1999) - A Premises on the Capital Market.

[38]. Strategic Financial Management Robert Alan Hill.

[39]. Strategic Management Neil Ritson.

[40]. Technical Analysis of Stock Trends 1948.

[41]. The one minute manager 1982.

[42]. Utility privatization and the poor in Nigeria Book by AdemolaAriyo 2005

[43]. Western and Irgam (1998) -Management Finance 6th Edition Macmillan International.

[44]. William 1 Stanton (1984): Fundamentals of Marketing 6th Edition, McGrawilill, Inc. USA pp 65-68.

[45]. Working Capital and Strategic Debtor Management Robert Alan Hill. 